\title{
Induced freezing tolerance and free amino acids perturbation of spinach by exogenous proline
}

\author{
Hyunsuk Shin $\cdot$ Sewon Oh $\cdot$ Daeil Kim $\cdot$ Jeum Kyu Hong $\cdot$ Jae Gil Yun $\cdot$ Sang Woo Lee $\cdot$ Ki-Ho Son
}

Received: 17 December 2018 / Revised: 17 December 2018 / Accepted: 17 December 2018

(C) Korean Society for Plant Biotechnology

\begin{abstract}
The objective of this study was to investigate whether exogenous proline (Pro) could confer freezing tolerance of spinach and determine fluctuations of free amino acids in spinach leaf tissues under freeze-induced stress. Treatment with Pro $(10 \mathrm{mM})$ resulted in more accumulation of Pro ( $\sim 2.6$-fold) in Pro-treated spinaches compared to untreated ones. These Pro-pretreated spinaches were more freezing-tolerant, showing more turgid leaves and petioles compared to untreated controls. However, when spinaches pre-treated with or without Pro were subjected to freezing, there was no significant difference in overall amino acid contents, emphasizing the role of Pro as an osmoprotectant. Freezing stress prompted intensification of total amino acid contents irrespective of pretreatment with Pro. Asp, Glu, Ala, and Val were the most abundant free amino acids due to increased protein degradation and nitrogen mobilization for plant survival under freezing stress. Arg, a precursor for the synthesis of polyamines in plants, was profoundly enhanced under freezing stress. This implies that Arg plays an important role in modulating freezing tolerance. Gly, Leu, and Ile were maintained at relatively low levels in all treatments. However, Ser, Tyr, and Lys as primary constituents of dehydrins were accumulated under freezing stress, suggesting that they might play a role in increasing cryoprotective activity under freezing stress.
\end{abstract}

Keywords Arginine, Aspartate, Freezing stress, Glutamate, Spinacia oleraceae, Valine

H. Shin $(\varangle) \cdot$ J. K. Hong · J. G. Yun · S. W. Lee · K. -H. Son Department of Horticulture, Gyeongnam National University of Science and Technology, Jinju, 52725, Korea

e-mail: shin@gntech.ac.kr

S. Oh $\cdot$ D. Kim

Department of Horticulture, Chungbuk National University, Cheongju 28644, Korea

\section{Introduction}

Freezing stress frequently causes structural and functional cellular damages due to extracellular ice crystals and intracellular dehydration. It consequently leads to limited yield and distribution of plants. Ability of plants to counteract such freezing effect with erratic temperature patterns which compel premature deacclimation followed by a cold backlash (Arora 2013) has critical importance for their survival against spring frost.

Freezing stress at molecular levels also makes plants suffer biochemical strains such as excessive production of reactive oxygen species (ROS) during electron transport processes in photosynthesis and mitochondrial respiration. It also causes perturbation of amino acids, carbohydrates, and lipid metabolisms (Thomashow 1999).

Proline (Pro) is one of compatible solutes. It is widely known that Pro is accumulated in response to various abiotic stresses. It mainly serves as a mediator of osmotic adjustment, a chaperone in the cell, and a major component of cell wall structural proteins (Kavi Kishor and Sreenivasulu 2014). Pro accumulation is known to confer tolerance in response to salt or temperature stress in different species (Chu et al. 1974; Bagdi and Shaw 2013). Recently, some studies have demonstrated that exogenous Pro can mitigate detrimental effects of salt and cadmium stresses (Heuer 2003; Hoque et al. 2007; Islam et al. 2009). On the other hand, Pro accumulation does not necessarily lead to dehydration or saltstress tolerance in Arabidopsis thaliana (Liu and Zhu 1997; Nakashima et al. 1998). In our previous studies, contrary to our expectations largely based on published reports of Pro accumulation in response to cold stress in various herbaceous species (Chu et al. 1974; Duncan and Widholm 1987; Savouré et al. 1997; Hur et al. 2004), Pro accumulation of peach shoots was likely a response to activation of metabolism associated with growth resumption in eco-dormant shoots at relatively high temperatures to be conducive for growth 
(Shin et al. 2016). Therefore, the relationship between Pro accumulation and abiotic stress tolerance in plants does not seem to be universal. Furthermore, the critical correlation between Pro synthesis and freezing stress in spinach (Spinacia oleraceae L.) has not been investigated yet.

Amino acids including Pro are precursors and constituents of proteins. They are also mobilized as precursors of other nitrogen compounds. Several studies have reported that free amino acids such as Asp, Ser, Gly, and Pro are accumulated in response to drought and osmotic stresses in different species (Hanower and Brzozowska 1975; Yang et al. 2000; Di Martino et al. 2003). Although the correlation between Pro and abiotic stresses has been of interest in many studies, correlations of other free amino acids with abiotic stresses have been less studied.

Spinach, an important horticultural crop, is susceptible to abrupt and unseasonable spring frost, frequently resulting in frost damage and economic losses. Frequency of such injury is expected to increase progressively with vagaries of climate change. Therefore, discovering cultural practices or strategies to ameliorate freezing tolerance would be beneficial to the horticulture industry.

Thus, objective of this study was to investigate whether exogenous Pro could confer freezing tolerance of spinach and determine fluctuations of free amino acids in spinach leaf tissues under freeze-induced stress. Here, our results showed obvious evidence that exogenous Pro could confer freezing stress-tolerance. This was confirmed through phenotypic observations of frozen spinach plants. Our results also provide beneficial information about fluctuations of free amino acids in response to freeze-induced stress in spinach leaf tissues. Furthermore, our results suggest that a practical application of exogenous Pro for freezing tolerance improvement is feasible through further research.

\section{Materials and Methods}

Plant material and Pro treatment

Spinach cv. Modurang7 seeds (Sakata Korea, Seoul, Korea) were germinated and grown in plastic pots $(10.6 \times 10.6 \times$ $11.5 \mathrm{~cm}, \mathrm{~L} \times \mathrm{W} \times \mathrm{H})$ containing Baroker medium soil (Seoul Bio, Eumsung, Korea) in April 2015. The average light intensity of $\sim 335 \mu \mathrm{mol} \cdot \mathrm{m}^{-2} \cdot \mathrm{s}^{-1}$ at seedling height was applied at $25 / 18^{\circ} \mathrm{C}(\mathrm{D} / \mathrm{N})$ with a 13.5 -h natural photoperiod in a greenhouse. These seedlings were bottom-watered as needed every 4 or 5 days. Three weeks later, while controls were only bottom-irrigated with half strength of Hoagland's nutrition solution (Hoagland and Arnon 1950) for two weeks, Pro-pretreatment was supplied by adding $10 \mathrm{mM}$ Pro to the nutrition solution for the same period. In olive trees and tobacco cells, $20 \sim 25 \mathrm{mM}$ Pro was used for exogenous Pro treatment (Hoque et al. 2007; Ahmed et al. 2010). Based on these studies, $10 \mathrm{mM}$ Pro was selected for exogenous application. Any visual damage at this concentration was not observed (Table 1). Five-week-old seedlings were used for respective experiments described below.

Plant growth measurement

Plant growth was evaluated by measuring length and number of two true leaves of four plants from each treatment. Data were obtained from two independent experiments, each with four replicates.

Freezing treatment

Pro-pretreated 5-week-old seedlings and controls were subjected to freezing stress. Referring to previous studies showing that $\mathrm{LT}_{50}$ of spinach leaf tissues was $\sim-5.5^{\circ} \mathrm{C}$ (Chen and Arora 2014; Min et al. 2014), freezing temperatures of 2.5/-1. $0^{\circ} \mathrm{C}\left(\mathrm{D} / \mathrm{N}\right.$; Max. 5.6, Min. $\left.-2.3^{\circ} \mathrm{C}\right)$ were used in a growth chamber with 13.5-h photoperiod with fluorescent light intensity of $\sim 350 \mu \mathrm{mol} \cdot \mathrm{m}^{-2} \cdot \mathrm{s}^{-1}$ for $48 \mathrm{~h}$ (Fig. 1).

Free amino acids extraction

Five leaves collected from each treatment were immediately ground in liquid $\mathrm{N}_{2}$ and stored as powder at $-80^{\circ} \mathrm{C}$ until use. The ground powder $(2 \mathrm{~g})$ was moved to a $50-\mathrm{mL}$ sample tube containing $30 \mathrm{~mL}$ of $1 \%$ sulfosalicylic acid and

Table 1 Length and number of spinach (Spinacia oleracea L. cv. Modurang7) leaves treated with either 50\% Hoagland solution (control) or $10 \mathrm{mM}$ Pro for two weeks

\begin{tabular}{|c|c|c|c|}
\hline \multirow{2}{*}{ Treatment } & \multicolumn{2}{|c|}{ Leaf length $(\mathrm{cm})$} & \multirow{2}{*}{ Number of leaves } \\
\hline & $1 \mathrm{st}$ & 2nd & \\
\hline Before treatment & $8.4^{z}$ & 8.2 & 5.5 \\
\hline Control & $16.5 \mathrm{NS}^{\mathrm{z}}$ & 15.3 NS & $10.0 \mathrm{NS}$ \\
\hline Pro & $14.2 \mathrm{NS}^{\mathrm{z}}$ & 14.4 NS & $8.9 \mathrm{NS}$ \\
\hline
\end{tabular}

${ }^{2} \mathrm{NS}$ indicates not significant between treatments by Student's t-test $(p<0.05)$. 


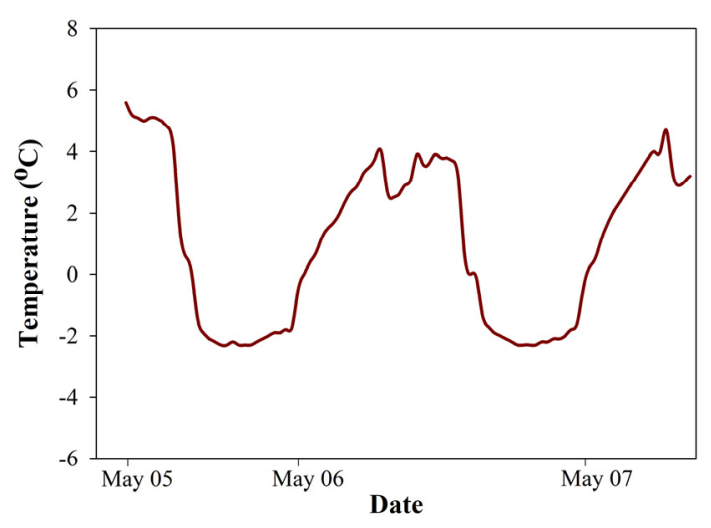

Fig. 1 Freezing temperatures at an average of $2.5 /-1.0^{\circ} \mathrm{C}(\mathrm{D} / \mathrm{N}$; Max. 5.6, Min. $-2.3^{\circ} \mathrm{C}$ ) applied in a growth chamber with 13.5 -h photoperiod at fluorescent light intensity of $\sim 350 \mu \mathrm{mol} \cdot \mathrm{m}^{-2} \cdot \mathrm{s}^{-1}$ for $48 \mathrm{~h}$

vortexed for $1 \mathrm{~min}$. Supernatants were obtained by two successive centrifugations (at $1,348 \times \mathrm{g}$ for $10 \mathrm{~min}$ and at $16,582 \times g$ for $20 \mathrm{~min}$, respectively) at room temperature. These supernatants were filtered using $0.2-\mu \mathrm{m}$ nylon syringe filter (Advantec, Tokyo, Japan).

Analysis of amino acids

Free amino acid quantification was performed using an amino acid analyzer (Hitachi L-8900, Tokyo, Japan) equipped with Hitachi HPLC packed column, ion-exchanging resin No. $2622 \mathrm{PF}(4.6 \times 60 \mathrm{~mm})$, and a UV detector (VIS1: $570 \mathrm{~nm}$, VIS2: $440 \mathrm{~nm})$. A series of Kanto L-8500 buffer solutions
(PF-1, 2, 3, 4 and RG; Kanto Chemical Co., Tokyo, Japan) were used as mobile phase. Each sample $(20 \mu \mathrm{L})$ was injected and its amino acid concentration was assessed using ninhydrin reagent set (Wako Chemicals Inc., Osaka, Japan). Data were obtained from two independent experiments, each with three technical replicates.

Statistical analysis

Statistically significant differences of data were confirmed using analysis of variance (ANOVA) with SAS 9.4 software package (SAS Institute Inc., Cary, NC, USA). Data were processed using SigmaPlot 12.5 (Systat Software, Inc., San Jose, CA, USA).

\section{Results}

Growth and freezing tolerance of Pro-uptaken spinach

Pro supplied by bottom-watering for two weeks was absorbed well from roots of spinaches. Pro content in Pro-treated group was $0.978 \mu \mathrm{mol} \cdot 20 \mu \mathrm{L}$, which was significantly higher than that $(0.372 \mu \mathrm{mol} \cdot 20 \mu \mathrm{L})$ in the control group (Table 2). However, there was no significant difference in number or length of leaves at two weeks after Pro treatment between the two groups (Table 1, Refer to Fig. 2). After exposing to freezing stress for $48 \mathrm{~h}$, Pro-pretreated spinaches showed discernible changes in comparison with

Table 2 Concentration ( $\mu \mathrm{mol} \cdot 20 \mu \mathrm{L})$ of free amino acids in freeze-injured spinach (Spinacia oleracea L. cv. Modurang7) leaves pretreated with either $50 \%$ Hoagland solution (control) or $10 \mathrm{mM}$ Pro for two weeks

\begin{tabular}{lcccc}
\hline \multirow{2}{*}{ Amino acid } & \multicolumn{5}{c}{ Treatment $^{\mathrm{z}}$} \\
\cline { 2 - 5 } Control & $3.487 \pm 0.046 \mathrm{~b}$ & $3.668 \pm 0.006 \mathrm{~b}$ & $9.190 \pm 0.010 \mathrm{a}$ & $8.019 \pm 0.019 \mathrm{a}$ \\
Asp & $3.260 \pm 0.042 \mathrm{c}$ & $5.702 \pm 0.007 \mathrm{~b}$ & $8.337 \pm 0.009 \mathrm{a}$ & $7.660 \pm 0.005 \mathrm{a}$ \\
Ser & $1.22 \pm \pm 0.018 \mathrm{~b}$ & $1.207 \pm 0.002 \mathrm{~b}$ & $1.791 \pm 0.001 \mathrm{a}$ & $1.882 \pm 0.004 \mathrm{a}$ \\
Ala & $0.968 \pm 0.011 \mathrm{~b}$ & $0.701 \pm 0.001 \mathrm{~b}$ & $1.828 \pm 0.019 \mathrm{a}$ & $2.162 \pm 0.004 \mathrm{a}$ \\
Val & $0.457 \pm 0.006 \mathrm{~b}$ & $0.403 \pm 0.001 \mathrm{~b}$ & $1.903 \pm 0.002 \mathrm{a}$ & $0.975 \pm 0.002 \mathrm{ab}$ \\
Pro & $0.372 \pm 0.014 \mathrm{~b}$ & $0.978 \pm 0.025 \mathrm{a}$ & $0.514 \pm 0.011 \mathrm{~b}$ & $0.671 \pm 0.017 \mathrm{ab}$ \\
Thr & $0.223 \pm 0.004 \mathrm{bc}$ & $0.203 \pm 0.001 \mathrm{c}$ & $0.411 \pm 0.000 \mathrm{a}$ & $0.334 \pm 0.001 \mathrm{ab}$ \\
Arg & $0.104 \pm 0.002 \mathrm{~b}$ & $0.045 \pm 0.001 \mathrm{~b}$ & $1.899 \pm 0.002 \mathrm{a}$ & $1.610 \pm 0.003 \mathrm{a}$ \\
Leu & $0.142 \pm 0.007 \mathrm{~b}$ & $0.089 \pm 0.001 \mathrm{~b}$ & $0.784 \pm 0.010 \mathrm{a}$ & $0.402 \pm 0.001 \mathrm{ab}$ \\
Gly & $0.119 \pm 0.001 \mathrm{a}$ & $0.104 \pm 0.001 \mathrm{~b}$ & $0.099 \pm 0.003 \mathrm{~b}$ & $0.098 \pm 0.001 \mathrm{~b}$ \\
Phe & $0.101 \pm 0.030 \mathrm{ab}$ & $0.061 \pm 0.001 \mathrm{~b}$ & $0.198 \pm 0.027 \mathrm{a}$ & $0.098 \pm 0.001 \mathrm{ab}$ \\
Tyr & $0.096 \pm 0.017 \mathrm{~b}$ & $0.052 \pm 0.001 \mathrm{~b}$ & $0.282 \pm 0.021 \mathrm{a}$ & $0.140 \pm 0.001 \mathrm{ab}$ \\
Ile & $0.086 \pm 0.001 \mathrm{~b}$ & $0.068 \pm 0.000 \mathrm{~b}$ & $0.427 \pm 0.003 \mathrm{a}$ & $0.241 \pm 0.000 \mathrm{ab}$ \\
Lys & $0.040 \pm 0.001 \mathrm{~b}$ & $0.020 \pm 0.001 \mathrm{~b}$ & $0.242 \pm 0.001 \mathrm{a}$ & $0.106 \pm 0.000 \mathrm{ab}$ \\
\hline Sum & $10.685 \pm 0.076 \mathrm{~b}$ & $13.301 \pm 0.034 \mathrm{~b}$ & $27.904 \pm 0.019 \mathrm{a}$ & $24.397 \pm 0.037 \mathrm{a}$ \\
\hline
\end{tabular}

${ }^{\mathrm{z}}$ For each amino acid, different letters indicate significant differences between treatments according to Duncan's multiple range test $(p<0.05)$. 

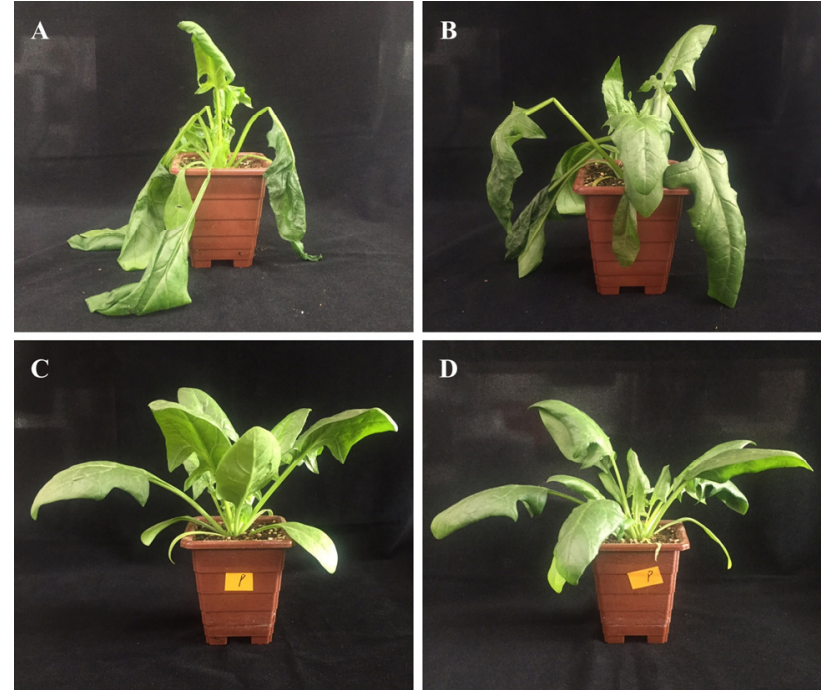

Fig. 2 Representative visuals of freeze-injured spinaches (Spinacia oleracea L. cv. Modurang7) pretreated with either 50\% Hoagland solution (A, B) or $10 \mathrm{mM}$ Pro (C, D) for two weeks

control spinaches (Fig. 2). Although Pro-pretreated spinaches showed healthier appearance, petioles of control spinaches without Pro-pretreatment were broken and their leaves were water-soaked (Fig. 2A, 2B), meaning that Pro-pretreated ones possessed much higher freezing tolerance than control ones without such pretreatment (Fig. 2C, 2D).

Free amino acids involved in enhancement of freezing tolerance of Pro-uptaken spinach

In controls, the five most abundant amino acids were Asp, Glu, Ser, Ala, and Val in order, accounting for $\sim 88 \%$ of the overall amount of amino acids. The other nine amino acids (Pro, Thr, Arg, Leu, Gly, etc.) made up the rest (Table 2). However, in Pro-treated ones, the five most abundant amino acids were Glu, Asp, Ser, Pro, and Ala in order. Contents of Glu and Pro were increased significantly in Pro-treated leaves compared to those in controls. However, content of Gly was decreased in Pro-treated leaves. Other amino acids did not show significant changes in their contents after Pro-treatment.

Interestingly, freezing stress induced strong augmentation of total amino acid content regardless whether leaves were pretreated with Pro. Total amino acid contents of frozen controls were $\sim 2.8$-fold higher than those of unfrozen ones. Contents of all investigated amino acids except Gly were increased. Asp, Glu, Ser, Ala, and Val were still the most abundant amino acids after freezing, accounting for $\sim 83 \%$ of the total amino acid content. Particularly profound increase of Arg content was detected (approx. 18-fold over unfrozen controls). By comparison, total amino acid contents of frozen
Pro-pretreated spinaches were approximately 1.8-fold higher than those of unfrozen Pro-pretreated ones. Just like frozen controls, enhancement in contents of Asp, Glu, Ser, Ala, Val, and Arg was observed.

\section{Discussion}

There is increasing evidence that exogenous compounds such as salicylic acid, glycine betaine, and Pro have beneficial effects in that they can ameliorate abiotic stresses of plants (Ashraf and Foolad 2007; Shin et al. 2018). However, research on the effect of exogenous Pro on improvement of freezing tolerance remains scarce.

In plants, Pro as a compatible solute has multiple functions such as osmoregulation, protection of membrane integrity, function as a molecular chaperone under various abiotic stresses (Kavi Kishor and Sreenivasulu 2014). In the present study, $10 \mathrm{mM}$ Pro application was accomplished by bottomwatering for two weeks. It was absorbed well from roots of spinaches and transported to leaves. This was confirmed by analysis of free amino acids in spinach leaf tissues (Table 2). Pro-treated spinaches accumulated Pro up to 2.6-fold compared to untreated ones. These Pro-pretreated spinaches were much more tolerant against freezing stress, showing more turgid leaves and petioles compared to untreated controls (Fig. 2). However, there was no significant difference in overall amino acid content after freezing stress between the two treatments. Therefore, the osmoprotective role of Pro was emphasized through these experiments.

Pro is synthesized primarily via the Glu pathway in the cytosol (Szabados and Savouré 2010). Pro biosynthesis is related to two enzymes: pyrroline-5-carboxylate (P5C) synthase (P5CS) and P5C reductase (P5CR). These enzymes catalyze conversions from Glu to Glu-semialdehyde (GSA) and from P5C to Pro, respectively (Nakashima et al. 1998). We observed that Pro-treated spinaches accumulated precursor Glu and Pro. Our data indicate that Pro application can affect the perturbation of Pro biosynthetic process. For this reason, Pro-uptaken plants were more freezing-tolerant than untreated ones. However, Pro accumulation was also shown in untreated ones (Table 2). Data from many reports have indicated that osmotic-stressed plants will accumulate significantly more Pro compared to non-stressed ones. Such Pro increase has been considered as a response for osmotic stress acclimation or adaptation (Delauney and Verma 1993). In our previous study, Pro was also significantly enhanced ( $\sim 28$-fold) during cold acclimation at $4^{\circ} \mathrm{C}$ for 9 days in comparison with non-acclimated spinaches (Shin et al. 2018).

Pro can alternatively be synthesized from ornithine which 
is transaminated by Orn- $\delta$-aminotransferase, producing GSA and $\mathrm{P} 5 \mathrm{C}$ in mitochondria followed by P5CR catalytic activity in the cytosol (Delauney et al. 1993; Roosens et al. 1998). Previous studies have reported that Pro synthesis is mainly stimulated via the Orn pathway under abiotic stress and spring growth resumption in some species (Lee and Chang 1999; Shin et al. 2016). However, in our results, Orn was not detected due to its very small amount. Our results thus suggest that Pro of spinaches is synthesized primarily via the Glu pathway.

Amino acids are precursors and constituents of proteins. They are also mobilized as precursors of other nitrogen compounds. However, changes of free amino acids against abiotic stresses have been less studied. In most plants, a spectra of amino acids found in phloem and xylem appear to be similar and major components are amides such as Gln and Asn and acidic amino acids such as Glu and Asp (Fischer et al. 1998). In spinaches, Asp and Glu were most abundant amino acides irrespective of Pro and/or freezing treatments. After exposure to freezing stress, Asp, Glu, Ala, and Val were still the most abundant (Table 2). When plants are stressed by certain environmental factors, such amino acids are significantly enhanced by increased protein degradation and conversion to available nitrogen in plant tissues for their survival (White 1984).

Notably, profound increase of Arg was observed in both treatment groups after freezing stress (about 18-fold over unfrozen controls). Arg is a medium for transport and storage of nitrogen. It is also a precursor for the synthesis of other amino acids and polyamines in plants (Flores et al. 2008; Brauc et al. 2012). Major accumulation of polyamines (putrescine, spermidine and spermine) during cold acclimation has been observed in many plants (Kushad and Yelenosky 1987; Nadeau et al. 1987). In addition, recent research has established that knock out Arabidopsis mutants of AtARGAHs (also known as arginase or Arg amidohydrolase) exhibit enhanced tolerances to multiple abiotic stresses including water deficit, salt, and freezing stresses while AtARGAHs-overexpressing lines showed reduced abiotic stress tolerance (Shi et al. 2013). However, in our data, Arg content of spinaches was enhanced strongly regardless whether spinaches were freezing-tolerant or susceptible.

Although Ser, Tyr, and Lys contents were not changed by Pro treatment, they were increased significantly in response to freezing stress. These amino acids are major components of dehydrin proteins. Dehydrins have generally been classified based on their structural features such as the presence of conserved sequences designated as Y-, Sand K-segments (Allagulova et al. 2003). They are one of several proteins known to have cryoprotective activity under cold stress in several plant species (Wisniewski et al. 1999; Zhang et al. 2011).

Gly and Ser have been strongly related to photorespiratory cycle (Lea et al. 1990). In early stage of salt stress, their increases are correlated with increased photorespiration rate (Di Martino et al. 2003). However, in our data, Ser content was increased but Gly content was decreased in response to freezing stress. Thus, neither of the two amino acids seems to be related to photorespiration in this study. Leu and Ile were somewhat accumulated under freezing stress. However, their levels were relatively low in all treatment groups. Information about changes of these amino acids in response to stress conditions has been rarely reported. Leu or Ile did not show any change for protein synthesis or degradation under mild salt stress (Robinson et al. 1992; Di Martino et al. 2003).

Taken together, Pro treatment accumulated Pro to $\sim 2.6$-fold in Pro-treated spinaches compared to that in untreated ones. Pro-pretreated spinaches were much more freezing-tolerant, showing more turgid leaves and petioles compared to untreated controls. However, there was no significant difference in overall amino acid contents between the two treatment groups, emphasizing osmoprotective role of Pro. Freezing stress induced strong augmentation of total amino acid content regardless whether spinaches were pretreated with Pro or not. Asp, Glu, Ala, and Val were the most abundant amino acids. This might be due to increased protein degradation and conversion to available nitrogen in plant tissues to cope with the freezing stress. Particularly profound increase of Arg was detected. This implies that Arg plays an important role in modulating freezing tolerance. Enhancement of Ser, Tyr and Lys as major components of dehydrin proteins might increase cryoprotective activity of spinaches under freezing stress. However, other amino acids (Gly, Leu, and Ile) remained at relatively low levels in all treatment groups.

\section{Acknowledgements}

This work was supported by Gyeongnam National University of Science and Technology Grant in 2017.

\section{References}

Ahmed CB, Rouina BB, Sensoy S, Boukhriss M, Abdullah FB (2010) Exogenous proline effects on photosynthetic performance and antioxidant defense system of young olive tree. J Agric 
Food Chem 58:4216-4222

Allagulova CR, Gimalov FR, Shakirova FM, Vakhitov VA (2003) The plant dehydrins: structure and putative functions. Biochemistry (Moscow) 68:945-951

Arora R (2013) Physiological study of the components of winter-hardiness in Rhododendron: cold acclimation, deacclimation kinetics, and reacclimation ability. Acta Hortic 990:67-81

Ashraf M, Foolad MR (2007) Roles of glycine betaine and proline in improving plant abiotic stress resistance. Environ Exp Bot 59:206-216

Bagdi DL, Shaw BP (2013) Analysis of proline metabolic enzymes in Oryza sativa under $\mathrm{NaCl}$ stress. J Environ Biol 34:677-681

Brauc S, de Vooght E, Claeys M, Geuns JMC, Höfte M, Angenon G (2012) Overexpression of arginase in Arabidopsis thaliana influences defence responses against Botrytis cinerea. Plant Biol 14:39-45

Chen K, Arora R (2014) Understanding the cellular mechanism of recovery from freeze-thaw injury in spinach: possible role of aquaporins, heat shock proteins, dehydrin and antioxidant system. Physiol Plant 150:374-387

Chu, TM, Aspinall D, Paleg LG (1974) Stress metabolism. VI. Temperature stress and the accumulation of proline in barley and radish. Aust J Plant Physiol 1:87-97

Delauney AJ, Hu CAA, Kavi Kishor PB, Verma DPS (1993) Cloning of ornithine $\delta$-aminotransferase cDNA from Vigna aconitifolia by trans-complementation in Escherichia coli and regulation of proline biosynthesis. J Biol Chem 268: 18673-18678

Delauney AJ, Verma DPS (1993) Proline biosynthesis and osmoregulation in plants. Plant J 4:215-223

Di Martino C, Delfine S, Pizzuto R, Loreto F, Fuggi A (2003) Free amino acids and glycine betaine in leaf osmoregulation of spinach responding to increasing salt stress. New Phytol 158:455-463

Duncan DR, Widholm JM (1987) Proline accumulation and its implication in cold tolerance of regenerable maize callus. Plant Physiol 83:703-708

Fischer W-N, André B, Rentsch D, Krolkiewicz S, Tegeder M, Breitkreuz K, Frommer WB (1998) Amino acid transport in plants. Trends Plant Sci 3:188-195

Flores T, Todd CD, Tovar-Mendez A, Dhanoa PK, CorreaAragunde N, Hoyos ME, Brownfield DM, Mullen RT, Lamattina L, et al (2008) Arginase-negative mutants of Arabidopsis exhibit increased nitric oxide signaling in root development. Plant Physiol 147:1936-1946

Hanower P, Brzozowska J (1975) Effects of osmotic stress on composition of free amino acids in cotton leaves. Phytochemistry 14:1691-1694

Heuer B (2003) Influence of exogenous application of proline and glycinebetaine on growth of salt-stressed tomato plants. Plant Sci 165:693-699

Hoagland DR, Arnon DI (1950) The water-culture method for growing plants without soil. 2nd ed. Circular, California Agricultural Experiment Station, p 347
Hoque MA, Okuma E, Banu MNA, Nakamura Y, Shimoishi Y, Murata Y (2007) Exogenous proline mitigates the detrimental effects of salt stress more than exogenous betaine by increasing antioxidant enzyme activities. J Plant Physiol 164:553-561

Hur J, Jung KH, Lee CH, An G (2004) Stress-inducible OsP5CS2 gene is essential for salt and cold tolerance in rice. Plant Sci 167:417-426

Islam MM, Hoque MA, Okuma E, Banu MNA, Shimoishi Y, Nakamura Y, Murata Y (2009) Exogenous proline and glycinebetaine increase antioxidant enzyme activities and confer tolerance to cadmium stress in cultured tobacco cells. J Plant Physiol 166:1587-1597

Kavi Kishor PB, Sreenivasulu N (2014) Is proline accumulation per se correlated with stress tolerance or is proline homeostasis a more critical issue? Plant Cell Environ 37:300-311

Kushad MM, Yelenosky G (1987) Evaluation of polyamine and proline levels during low temperature acclimation of citrus. Plant Physiol 84:692-695

Lea PJ, Robinson SA, Stewart GR (1990) The enzymology and metabolism of glutamine, glutamate and asparagine. In Miflin BJ, ed, The biochemistry of plants. Academic Press, New York, USA, pp 121-169

Lee TM, Chang YC (1999) An increase of ornithine $\delta$ aminotransferase-mediated proline synthesis in relation to high-temperature injury in Gracilaria temuistipitata (Gigartinales, Rhodophyta). J Phycol 35:84-88

Liu J, Zhu JK (1997) Proline accumulation and salt-stress induced gene expression in a salt-hypersensitive mutant of Arabidopsis. Plant Physiol 114:591-596

Min K, Chen K, Arora R (2014) Effect of short-term versus prolonged freezing on freeze-thaw injury and post-thaw recovery in spinach: importance in laboratory freeze-thaw protocols. Environ Exp Bot 106:124-131

Nadeau P, Delaney S, Chouinard L (1987) Effects of cold hardening on the regulation of polyamine levels in wheat (Triticum aestivum L.) and alfalfa (Medicago sativa L.). Plant Physiol 84:73-77

Nakashima K, Satoh R, Kiyosue T, Yamaguchi-Shinozaki K, Shinozaki K (1998) A gene encoding proline dehydrogenase is not only induced by proline and hypoosmolarity, but is also developmentally regulated in the reproductive organs of Arabidopsis. Plant Physiol 118:1233-1241

Robinson SA, Stewart GR, Philips R (1992) Regulation of glutamate dehydrogenase activity in relation to carbon limitation and protein catabolism in carrot cell suspension culture. Plant Physiol 98:1190-1195

Roosens NH, Thu TT, Iskandar HM, Jacobs M (1998) Isolation of the ornithine-delta-aminotransferase cDNA and effect of salt stress on its expression in Arabidopsis thaliana. Plant Physiol 117:263-271

Savouré A, Hua XJ, Bertauche N, van Montagu M, Verbruggen N (1997) Abscisic acid-independent and abscisic acid-dependent regulation of proline biosynthesis following cold and osmotic stresses in Arabidopsis thaliana. Mol Gen Genet 254:104-109 
Shi H, Ye T, Chen F, Cheng Z, Wang Y, Yang P, Zhang Y, Chan $\mathrm{Z}$ (2013) Manipulation of arginase expression modulates abiotic stress tolerance in Arabidopsis: effect on arginine metabolism and ROS accumulation. J Exp Bot 64:1367-1379

Shin H, Min K, Arora R (2018) Exogenous salicylic acid improves freezing tolerance of spinach (Spinacia oleraceae L.) leaves. Cryobiology 81:192-200

Shin H, Oh S, Arora R, Kim D (2016) Proline accumulation in response to high temperature in winter-acclimated shoots of Prunus persica: a response associated with growth resumption or heat stress? Can J Plant Sci 96:630-638

Szabados Z, Savouré A (2010) Proline: a multifunctional amino acid. Trends Plant Sci 15:89-97

Thomashow MF (1999) Plant cold acclimation: freezing tolerance genes and regulatory mechanisms. Annu Rev Plant Physiol
Plant Mol Biol 50:571-599

White TCR (1984) The abundance of invertebrate herbivores in relation to the availability of nitrogen in stressed food plants. Oecologia 63:90-105

Wisniewski ME, Webb R, Balsamo R, Close TJ, Yu XM, Griffith M (1999) Purification, immunolocalization, cryoprotective, and antifreeze activity of PCA60: a dehydrin from peach (Prunus persica). Physiol Plant 105:600-608

Yang CW, Lin CC, Kao CH (2000) Proline, ornithine, arginine and glutamic acid contents in detached rice leaves. Biol Plant 43:305-307

Zhang X, Wang K, Ervin EH, Waltz C, Murphy T (2011) Metabolic changes during cold acclimation and deacclimation in five bermudagrass varieties. 1. Proline, total amino acid, protein, and dehydrin expression. Crop Sci 51:838-846 